\title{
Clinical and radiographic findings in patients with chondrocalcinosis
}

\author{
Paulina Vele', Laura Otilia Damian², Siao-Pin Simon ${ }^{1,2}$, Ioana Felea ${ }^{1,2}$, Laura Muntean ${ }^{1,2}$, \\ Ileana Filipescu1,2, Maria Magdalena Tamas ${ }^{1,2}$, Cristina Pamfil', Simona Rednic ${ }^{1,2}$ \\ 1"Iuliu Hatieganu” University of Medicine and Pharmacy, Cluj-Napoca, Romania \\ ${ }^{2}$ Rheumatology, Emergency County Teaching Hospital, Cluj-Napoca, Romania
}

\begin{abstract}
Background. Calcium pyrophosphate deposition disease results from the deposition of calcium pyrophosphate crystals and needs to fulfil McCarty criteria for diagnosis. Chondrocalcinosis is defined as cartilage and fibrocartilage calcification identified by imaging or histological examination. The presence of calcium-containing crystals in synovial fluid is associated strongly with the degenerative joint disease, but the exact mechanism remains to be elucidated.

Objectives. To compare the clinical and radiographic characteristics in patients with and without chondrocalcinosis.

Material and methods. One hundred and forty-three patients, 86 with chondrocalcinosis and 57 controls with primary osteoarthritis were consecutively enrolled in this case-control, transversal, prospective study performed in the Rheumatology Department, Emergency Clinical County Hospital Cluj-Napoca, Romania, between January 2015 and January 2018. A subgroup of 39 patients fulfilled McCarty criteria for calcium pyrophosphate deposition (CPPD) disease. Demographic data, clinical data, laboratory data, knee radiographs, knee ultrasound, were recorded in both groups. Kellgren-Lawrence score was graded in all patients at the knee level.

Results. The patients with chondrocalcinosis had higher tender joint count $(3.1 \pm 6.8$ versus $1.9 \pm 0.1, p<0.05)$, swollen joint count $(1.37 \pm 0.9$ versus $0.28 \pm 0.3, p<0.05)$, visual analogue scale for pain $(7.72 \pm 1.28$ versus $6.5 \pm 3.5$, $p<0.05)$. Kellgren-Lawrence score at the knee level was higher in the chondrocalcinosis group $(p<0.05)$ comparing to controls, but not when comparing the CPPD group with the chondrocalcinosis group. Osteoarthritis was associated with chondrocalcinosis when compared to controls and with definite CPPD when comparing to chondrocalcinosis subgroup.

Conclusions. Chondrocalcinosis was associated with pain, arthritis and higher Kellgren-Lawrence score than the controls.
\end{abstract}

Keywords: chondrocalcinosis, CPPD, Kellgren-Lawrence score, osteoarthritis

\section{INTRODUCTION}

Calcium pyrophosphate deposition (CPPD) disease is due to deposition of calcium pyrophosphate crystals in hyaline cartilage, fibrocartilage and soft tissues. The definite diagnosis of CPPD is the fulfiling of McCarty criteria which includes identification of crystals in synovial fluid analysis and typical radiographic calcifications $(1,2)$. The most affected joints by CPPD are the knees, symphysis pubis, wrists, hips, elbows. Abhishek et al found that in the absence of knee involvement, wrists and hips are the most affected (3). Radiographic evidence of hyaline cartilage and fibrocartilage calcification is named chondrocalcinosis. The radiological patterns de- scribed in patients with CPPD are a thin, parallel line with the articular surface in hyaline cartilage calcification; punctate fibrocartilage calcifications; calcifications of joint capsules, synovium, tendons, bursae and soft tissue. Resnick described that $98 \%$ of the cases with chondrocalcinosis could be identified by knee and pelvis radiographs $(4,5,6,7)$. In populational studies, radiography is used as a surrogate marker of CPPD.

Controversy still exists regarding the relationship between osteoarthritis and CPPD as a cause or consequence. The presence of calcium-containing crystals in synovial fluid is associated strongly with the degenerative joint disease, but the exact mechanism 
remains to be elucidated. The reports regarding radiographic changes are still controversial in patients with osteoarthritis and CPPD. It is not established if structural changes are different, more severe than in patients with primary osteoarthritis. In Chinese people, the prevalence of CPPD is lower, but the prevalence of osteoarthritis is higher $(8,9,10)$.

From different reports looks like that osteoarthritis with CPPD has some distinguishing features: a different distribution of joint involvement, the affected compartments, multiple, subchondral cysts, severe arthropathy, severe osteophytes, femoral condylar flattening, anterior femoral cortical erosion, suprapatellar effusion $(7,11,12,13)$.

The aim of this study was to compare the clinical and radiographic characteristics in patients with and without chondrocalcinosis.

\section{MATERIAL AND METHODS}

This was a case-control, transversal, prospective study performed in the Rheumatology Department, Emergency Clinical County Hospital Cluj-Napoca, Romania, between January 2015 and January 2018.

\section{Chondrocalcinosis group}

Patients presenting with evidence of CPPD (radiographic, by ultrasound or CPP crystal identification in synovial fluid) were consecutively included in the study. All patients had radiographic and ultrasound evidence of CPPD.

\section{Controls group}

Patients presenting with knee pain and primary osteoarthritis of the knee, without evidence of CPPD on ultrasound or on radiography at the knee level were consecutively included in the study.

From both groups were excluded patients with gout and other inflammatory rheumatic diseases.

Data about age (years), sex, weight $(\mathrm{kg})$, height $\left(\mathrm{m}^{2}\right)$, body mass index (BMI), number of tenders and swollen joints, visual analogue scale for pain (VAS), erythrocyte sedimentation rate (ESR) and C-reactive protein (CRP) were recorded in both groups. Also, information about joint trauma, meniscectomy, familial predisposition to CPPD and diuretics use.

The radiographic evidence of CPPD was considered a thin, parallel line with the articular surface (hyaline cartilage calcification) and punctate fibrocartilage calcification in the knees. The radiographs were taken in posteroanterior, weight-bearing semi- flexed view. Skyline view of patellofemoral joints was not taken in all patients, so we didn't consider them.

All radiographs were graded according to Kellgren-Lawrence score $(\mathrm{K} / \mathrm{L})$, a radiological score for severity of osteoarthritis. It has five grades: grade 0 (no radiographic features of osteoarthritis are present); grade 1 (doubtful joint space narrowing (JSN) and possible osteophytes); grade 2 (osteophytes and possible JSN); grade 3 (multiple osteophytes, definite JSN, sclerosis, possible bony deformity); grade 4 (large osteophytes, marked JSN, severe sclerosis and definite bony deformity)(14). Osteoarthritis was defined as a $\mathrm{K} / \mathrm{L}$ score $\geq 3$.

Ultrasound (US) examination was performed by the same rheumatologist using an Esaote My Lab 25 Gold with 5-10 and 10-18 MHz linear probes. The knees were examined by anterior scans with the knee in maximum flexion for the examination of hyaline cartilage and medial and lateral scans with the knee flexed at $30^{\circ}$ for fibrocartilage examination. Ultrasonographic evidence of CPPD was considered according to Frediani's ultrasound patterns $(15,16)$.

The synovial fluid analysis, when possible, was performed using polarized light microscopy. Calcium pyrophosphate crystals were considered the ones with weak birefringence and a rhomboid or parallelepipedic form.

All patients included in the study consented for participation and the approval of the University Ethics Committee was obtained.

Statistical analysis was performed using Microsoft Excel. We considered a level of $p<0.05$ statistically significant.

\section{RESULTS}

The study included 143 patients, 86 with chondrocalcinosis and 57 controls with primary osteoarthritis, matched for age and gender. Thirty-nine (45.34\%) of the patients with chondrocalcinosis had calcium pyrophosphate crystals in the synovial fluid and radiographic evidence of CPPD, fulfilling the McCarty criteria. The characteristics of the study population are presented in Table 1.

\section{Clinical assessment}

Regarding clinical characteristics, tender joint count (TJC), swollen joint count (SJC) and visual analogue scale for pain $(0-10)$ were higher in the chondrocalcinosis group comparing to controls 
$(\mathrm{p}<0.05)$. Patients from chondrocalcinosis group had a mild inflammatory syndrome, mean erythrocyte sedimentation rate (ESR) $22.89 \pm 458 \mathrm{~mm} / \mathrm{h}(\mathrm{p}<0.05)$ and mean C-reactive protein $2.54 \pm 39 \mathrm{mg} / \mathrm{dl}(\mathrm{p}=0.2)$ but higher comparative with the control group. Risk factors evaluated in this study are also presented in Table 1. All four patients with meniscectomy and joint injury had only knee chondrocalcinosis and with a mean $\mathrm{K} / \mathrm{L}$ score 3.16 .

TABLE 1. General and clinical characteristics of study participants

\begin{tabular}{|c|c|c|c|}
\hline Variable & $\begin{array}{l}\text { Chondrocalcinosis } \\
\text { group, } n=86\end{array}$ & $\begin{array}{c}\text { Controls } \\
\text { group, } n=57\end{array}$ & p-value \\
\hline Age (years) & $62.67 \pm 116$ & $59.46 \pm 75$ & 0.6 \\
\hline Height (m) & $1.67 \pm 0.0$ & $1.63 \pm 0.0$ & 0.02 \\
\hline Weight (kg) & $78 \pm 210$ & $76 \pm 182$ & 0.5 \\
\hline BMI $\left(\mathrm{kg} / \mathrm{m}^{2}\right)$ & $28.01 \pm 24$ & $28.5 \pm 23$ & 0.5 \\
\hline $\begin{array}{l}\text { Sex ratio of } \\
\text { male: female }\end{array}$ & $25: 62$ & $10: 46$ & 0.1 \\
\hline TJC & $3.1 \pm 6.8$ & $1.9 \pm 0.1$ & $p<0.05$ \\
\hline SJC & $1.37 \pm 0.9$ & $0.28 \pm 0.3$ & $p<0.05$ \\
\hline VAS & $7.72 \pm 1.28$ & $6.5 \pm 3.5$ & $p<0.05$ \\
\hline $\operatorname{ESR}(\mathrm{mm} / \mathrm{h})$ & $22.89 \pm 458$ & $12 \pm 51$ & $p<0.05$ \\
\hline $\mathrm{CRP}$ (mg/dl) & $2.54 \pm 39$ & $1.4 \pm 2.5$ & 0.2 \\
\hline Meniscectomy & 3* & $0 *$ & \\
\hline Joint injury & $1 *$ & $0 *$ & \\
\hline Diuretics & $14 *$ & $2 *$ & \\
\hline $\begin{array}{l}\text { The family } \\
\text { history of CPPD }\end{array}$ & $1^{*}$ & 0* & \\
\hline
\end{tabular}

BMI-body mass index; TJC-tender joint count; SJC-swollen joint count; VAS-visual analogue scale; ESR-erythrocyte sedimentation rate; CRP-C reactive protein; CPPD-calcium pyrophosphate deposition

\section{Radiographic characteristics}

Mean K/L score in the right knee and the left knee was significantly higher than the controls score $(\mathrm{p}<0.05)$. Average K/L score calculated as the average between right knee score and the left knee score was also higher than the controls score $(\mathrm{p}<0.05)$, (Table 2).

TABLE 2. Kellgren-Lawrence score in patients with chondrocalcinosis and controls

\begin{tabular}{|l|c|c|l|}
\hline K/L score & $\begin{array}{c}\text { Chondro- } \\
\text { calcinosis group, } \\
\mathbf{n = 8 6}\end{array}$ & $\begin{array}{c}\text { Controls } \\
\text { group, } \\
\mathbf{n = 5 7}\end{array}$ & $\mathbf{p}$ value \\
\hline $\begin{array}{l}\text { Right knee K/L } \\
\text { score }\end{array}$ & $2.57 \pm 1.2$ & $1.6 \pm 1.2$ & $\mathrm{p}<0.05$ \\
\hline Left knee K/L score & $2.4 \pm 1.2$ & $1.5 \pm 1.2$ & $\mathrm{p}<0.05$ \\
\hline Average K/L score & $2.5 \pm 1$ & $1.5 \pm 1.1$ & $\mathrm{p}<0.05$ \\
\hline \multicolumn{4}{|l|}{ Values are expressed as mean $\pm S D$} \\
\hline
\end{tabular}

$\mathrm{K} / \mathrm{L}$ score-Kellgren-Lawrence score
$\mathrm{K} / \mathrm{L}$ score $\geq 3$ in the right and left knee was associated with chondrocalcinosis (OR 5.22 [95\% CI 2.4-10.9] respectively 1.99 [95\% CI $1-3.6])$ (Table 3).

TABLE 3. Association between osteoarthritis and chondrocalcinosis

\begin{tabular}{|l|c|c|c|}
\hline K/L score & $\begin{array}{c}\text { Chondro- } \\
\text { calcinosis } \\
\text { group, } \mathbf{n = 8 6}\end{array}$ & $\begin{array}{c}\text { Controls } \\
\text { group } \\
\mathbf{n = 5 7}\end{array}$ & $\begin{array}{c}\text { OR } \\
\mathbf{( 9 5 \% ~ C l )}\end{array}$ \\
\hline Right knee K/L score <3 & 30 & 42 & 1 \\
\hline Right knee K/L score $\geq 3$ & 56 & 15 & $\begin{array}{c}5.22 \\
(2.4-10.9)\end{array}$ \\
\hline Left knee K/L score <3 & 31 & 46 & 1 \\
\hline Left knee K/L score $\geq 3$ & 55 & 11 & $\begin{array}{c}1.99 \\
(1-3.6)\end{array}$ \\
\hline
\end{tabular}

OR-Odds Ratio; 95\% Cl-95 \% confidence interval; K/L score-Kellgren-Lawrence score

From the total patients with chondrocalcinosis, 5 patients $(5.8 \%)$ had also hip osteoarthritis, 8 patients $(9.3 \%)$ hand osteoarthritis and 1 patient $(1.1 \%)$ ankle osteoarthritis.

\section{Radiographic findings in the CPPD subgroup and chondrocalcinosis subgroup}

CPPD subgroup included 39 patients which fulfilled McCarty Criteria and chondrocalcinosis subgroup included 47 patients diagnosed only by imaging studies.

According to the type of diagnosis CPPD or chondrocalcinosis, there wasn't a significative difference between patients diagnosed by McCarty criteria and those diagnosed by imaging (Table 4 ).

TABLE 4. Kellgren - Lawrence score in patients with CPPD and chondrocalcinosis

\begin{tabular}{|l|c|c|c|}
\hline & $\begin{array}{c}\text { CPPD by McCarty } \\
\text { criteria (synovial } \\
\text { fluid + imaging) } \\
\mathbf{N = 3 9}\end{array}$ & $\begin{array}{c}\text { CC by imaging } \\
\text { (radiography + } \\
\text { ultrasound) } \\
\mathbf{N = 4 7}\end{array}$ & P-value \\
\hline $\begin{array}{l}\text { Right knee K/L } \\
\text { score }\end{array}$ & $2.7 \pm 1.1$ & $2.4 \pm 1.4$ & 0.2 \\
\hline $\begin{array}{l}\text { Left knee K/L } \\
\text { score }\end{array}$ & $2.6 \pm 1.1$ & $2.3 \pm 1.2$ & 0.1 \\
\hline $\begin{array}{l}\text { Average K/L } \\
\text { score }\end{array}$ & $2.7 \pm 0.9$ & $2.4 \pm 1.1$ & 0.1 \\
\hline
\end{tabular}

CPPD - calcium pyrophosphate deposition disease; CC - chondrocalcinosis; K/L score-Kellgren-Lawrence score

$\mathrm{K} / \mathrm{L}$ score $\geq 3$ in the right and left knee was associated with CPPD (OR 3.7 [95\% CI 1.5-9.3] respectively 2.3 [95\% CI 0.9-5.8]) (Table 5). 
TABLE 5. Osteoarthritis in CPPD patients versus chondrocalcinosis patients

\begin{tabular}{|l|c|c|c|}
\hline & $\begin{array}{c}\text { CPPD by McCarty } \\
\text { criteria (synovial } \\
\text { fluid + imaging) } \\
\text { N=39 }\end{array}$ & $\begin{array}{c}\text { CC by imaging } \\
\text { (radiography } \\
\text { + ultrasound) } \\
\mathbf{N = 4 7}\end{array}$ & $\begin{array}{c}\text { OR } \\
(\mathbf{9 5 \%} \text { Cl) }\end{array}$ \\
\hline $\begin{array}{l}\text { Right knee } \\
\text { K/L score }<3\end{array}$ & 11 & 28 & 1 \\
\hline $\begin{array}{l}\text { Right knee } \\
\text { K/L score } \geq 3\end{array}$ & 28 & 19 & $\begin{array}{c}3.7 \\
(1.5-9.3)\end{array}$ \\
\hline $\begin{array}{l}\text { Left knee } \\
\text { K/L score }<3\end{array}$ & 10 & 21 & 1 \\
\hline $\begin{array}{l}\text { Left knee } \\
\text { K/L score } \geq 3\end{array}$ & 29 & 26 & $\begin{array}{c}2.3 \\
(0.9-5.8)\end{array}$ \\
\hline
\end{tabular}

CPPD-calcium pyrophosphate deposition disease; CC-chondrocalcinosis; K/L score-Kellgren-Lawrence score

\section{DISCUSSION}

This study examined clinical and radiographic characteristics in patients with and without CPPD. The existing studies are not homogenous because of the inclusion criterion which are based on different definitions and radiographic protocols.

The association between osteoarthritis and CPPD is established, but the most studies included patients with end-stage degenerative disease undergoing replacement surgery and different definition of osteoarthritis $(17,18,8)$.

There are a few theories about osteoarthritis and CPPD. First theory considers the deposition of calcium pyrophosphate crystals as a result of joint degeneration, joint damage and osteoarthritis $(19,20)$. Another theory is that the calcium pyrophosphate crystals induce changes in chondrocytes and cause the release of inflammatory cytokines and metalloproteases leading to cartilage degradation $(21,22)$. The calcification process is very complex and takes place also in other places than articular cartilage with some common mechanisms like altered differentiation of chondrocytes, ageing, deficiencies of calcification inhibitors, low-grade inflammation, apoptosis $(23,24)$. The processes described to promote both osteoarthritis and cartilage calcification are ageing, inflammatory cytokine expression, disordered chondrocyte differentiation, nitric oxide, dysregulated adenosine triphosphate and inorganic pyrophosphate metabolism and matrix modification (25). In the same editorial is explained why there are cases in which crystal deposition is not present in severe cartilage degeneration and cases in which crystal deposition is not associated with severe cartilage degeneration. This is explained by the predominance of the processes described above.
From a clinical point of view osteoarthritis associated with CPPD involves joints that are usually not involved in primary osteoarthritis like wrists, ankles, elbow.

Our results showed higher TJC, SJC, VAS and ESR in the chondrocalcinosis group. A similar result was found by Han et al regarding association with pain assessed by Western Ontario and McMaster Universities Arthritis Index (WOMAC) score but not with arthritis (26).

This study results showed that the means of K/L score and the average $\mathrm{K} / \mathrm{L}$ score (between the right and the left knee) are higher than the controls. We defined osteoarthritis as a K/L score $\geq 3$ and we found an association between chondrocalcinosis and osteoarthritis in both knees when compared to controls. The findings are similar to those of previous studies $(27,3)$.

Regarding the association with osteoarthritis in other joints in patients with chondrocalcinosis, we found the hand as the second site of osteoarthritis in patients with knee osteoarthritis. In another study, the hip was the second site followed by the wrist (28).

In our study, we did not find a significative difference in $\mathrm{K} / \mathrm{L}$ score between patients with defined CPPD and chondrocalcinosis. There is known the fact that in patients with imaging of chondrocalcinosis can be also basic calcium phosphate crystals because radiography is less sensitive than synovial fluid analysis in detecting calcium pyrophosphate crystals. Also, there is known the fact that the presence of basic calcium phosphate crystals is associated with OA severity $(29,30)$. Furthermore, K/L score $\geq 3$ was associated with CPDD when compared with chondrocalcinosis.

Our study has some limitations. First, the absence of synovial fluid analysis in all patients and skyline view of patellofemoral joints. Also, we didn't analyze the structural phenotypes in the knee joint, only the $\mathrm{K} / \mathrm{L}$ score (31). In a recent study were examined the structural phenotypes in patients with osteoarthritis and chondrocalcinosis. The study found an association with atrophic phenotype at the hip level and with attrition at the knee level. Also, at the knee level, there was no association between chondrocalcinosis and osteophytes and joint space narrowing (27).

\section{CONCLUSIONS}

Chondrocalcinosis was associated with more pain, arthritis and higher Kellgren-Lawrence score than the controls. 


\section{REFERENCES}

1. McCarty D.J. Calcium pyrophosphate dihydrate crystal deposition disease. Arthritis Rheum. 1976; 19(3 S):275-85.

2. Zhang W., Doherty M., Bardin T. et al. European league against rheumatism recommendations for calcium pyrophosphate deposition. Part I: Terminology and diagnosis. Ann Rheum Dis. 2011; 70(4):563-70.

3. Abhishek A., Doherty S., Maciewicz R. et al. Chondrocalcinosis is common in the absence of knee involvement. Arthritis Res Ther. 2012; 14(5)

4. Paparo F., Fabbro E., Ferrero G. et al. Imaging studies of crystalline arthritides. Reumatismo. 2011; 63: 263-75.

5. Thouverey C., Bechkoff G., Pikula S. et al. Inorganic pyrophosphate as a regulator of hydroxyapatite or calcium pyrophosphate dihydrate mineral deposition by matrix vesicles. Osteoarthr Cartil. 2009; 17(1):64-72.

6. Steinbach L.S. Calcium pyrophosphate dihydrate and calcium hydroxyapatite crystal deposition diseases: Imaging perspectives. Radiol Clin. North Am. 2004; 42:185-205.

7. Resnick D., Niwayama G., Goergen T.G. et al. Clinical, radiographic and pathologic abnormalities in calcium pyrophosphate dihydrate deposition disease (CPPD): pseudogout. Radiology. 1977;122(1):1-15.

8. Neame R.L., Carr A.J., Muir K. et al. UK community prevalence of knee chondrocalcinosis: Evidence that correlation with osteoarthritis is through a shared association with osteophyte. Ann Rheum Dis. 2003; 62(6):513-8.

9. Ramonda R., Musacchio E., Perissinotto E. et al. Prevalence of chondrocalcinosis in Italian subjects from northeastern Italy. The Pro.V.A. (PROgetto Veneto Anziani) Study. Clin Exp Rheumatol. 2009; 27(6):981-4.

10. Zhang Y., Terkeltaub R., Nevitt M. et al. Lower prevalence of chondrocalcinosis in Chinese subjects in Beijing than in white subjects in the United States: The Beijing osteoarthritis study. Arthritis Rheum. 2006; 54(11):3508-12.

11. Genant H.K. Roentgenographic aspects of calcium pyrophosphate dihydrate crystal deposition disease (pseudogout). Arthritis Rheum. 1976;19(3 S):307-28.

12. Martel W., McCarter D.K., Solsky M.A. et al. Further observations on the arthropathy of calcium pyrophosphate crystal deposition disease. Radiology 1981; 141(1):1-15.

13. Hansen S.E., Herning M. A comparative study of radiographic changes in knee joints in chondrocalcinosis, osteoarthrosis and rheumatoid arthritis. Scand J Rheumatol. 1984;13(1):85-92.

14. Kellgren J., Lawrence J. Radiological assessment of osteoarthritis. Ann Rheum Dis. 1957; 16(4):494.

15. Backhaus M., Burmester G.R., Gerber T. et al. Guidelines for musculoskeletal ultrasound in rheumatology. Ann Rheum Dise. 2001; 60: 641-9

16. Frediani B., Filippou G., Falsetti P. et al. Diagnosis of calcium pyrophosphate dihydrate crystal deposition disease: ultrasonographic criteria proposed. Ann Rheum Dis. 2005; 64:638-40.

17. Felson D.T., Anderson J.J., Naimark A. et al. The prevalence of chondrocalcinosis in the elderly and its association with knee osteoarthritis: The Framingham study. J Rheumatol. 1989; 16(9):1241-5.

18. Sanmarti R. Analysis of the association between chondrocalcinosis and osteoarthritis: A community based study. Ann Rheum Dis. 1996; 55(1):30-3.

19. Mitsuyama H., Healey R.M., Terkeltaub R.A. et al. Calcification of human articular knee cartilage is primarily an effect of aging rather than osteoarthritis. Osteoarthr Cartil. 2007; 15(5):559-65.

20. Neogi T., Nevitt M., Niu J. et al. Lack of association between chondrocalcinosis and increased risk of cartilage loss in knees with osteoarthritis: results of two prospective longitudinal magnetic resonance imaging studies. Arthritis Rheum. 2006; 54(6):1822-8.

21. Ea H.K., Nguyen C., Bazin D. et al. Articular cartilage calcification in osteoarthritis: Insights into crystal-induced stress. Arthritis Rheum. 2011; 63:10-8.

22. Ea H.K., Lioté F. Advances in understanding calcium-containing crystal disease. Curr Opin Rheumatol. 2009; 21:150-7.

23. Rutsch F., Terkeltaub R. Parallels between arterial and cartilage calcification: What understanding artery calcification can teach us about chondrocalcinosis. Curr Opin Rheumatol. 2003; 15: 302-10.

24. Rutsch F., Terkeltaub R. Deficiencies of physiologic calcification inhibitors and low-grade inflammation in arterial calcification: Lessons for cartilage calcification. Joint Bone Spine. 2005; 72:110-8.

25. Terkeltaub R.A. What does cartilage calcification tell us about osteoarthritis? J Rheumatol. 2002; 29(3):411-5.

26. Han B.K., Kim W., Niu J. et al. Association of Chondrocalcinosis in Knee Joints With Pain and Synovitis: Data From the Osteoarthritis Initiative. Arthritis Care Res. 2017; 69(11):1651-8.

27. Abhishek A., Doherty S., Maciewicz R.A. et al. Does Chondrocalcinosis Associate with a Distinct Radiographic Phenotype of Osteoarthritis in Knees and Hips? A Case-Control Study. Arthritis Care Res. 2016; 68(2):211-6.

28. Abhishek A., Doherty S., Maciewicz R. et al. Evidence of a systemic predisposition to chondrocalcinosis and association between chondrocalcinosis and osteoarthritis at distant joints: A cross-sectional study. Arthritis Care Res. 2013; 65(7):1052-8.

29. Olmez N., Schumacher H.R. Crystal deposition and osteoarthritis. Curr Rheumatol Rep.1999; 1(2):107-11.

30. Derfus B.A., Kurian J.B., Butler J.J. et al. The high prevalence of pathologic calcium crystals in pre-operative knees. J Rheumatol. 2002; 29(3):570-4.

31. Bierma-Zeinstra S.M.A., Verhagen A.P. Osteoarthritis subpopulations and implications for clinical trial design. Arthritis Res Ther. 2011; 13(2):213. 